\title{
Sedimentary metal bioavailability determined by the digestive constraints of marine deposit feeders: gut retention time and dissolved amino acids
}

\author{
Zhen Chen, Lawrence M. Mayer* \\ Darling Marine Center, University of Maine, Walpole, Maine 04573 , USA
}

\begin{abstract}
Contaminant metals bound to sediments are subject to considerable solubilization during passage of the sediments through the digestive systems of deposit feeders. We examined the kinetics of this process, using digestive fluids extracted from deposit feeders Arenicola marina and Parastichopus californicus and then incubated with contaminated sediments. Kinetics are complex, with solubilization followed occasionally by readsorption onto the sediment. In general, solubilization kinetics are biphasic, with an initial rapid step followed by a slower reaction. For many sediment-organism combinations, the reaction will not reach a steady state or equilibrium within the gut retention time (GRT) of the organisms, suggesting that metal bioavailability in sediments is a time-dependent parameter Experiments with commercial protein solutions mimic the kinetic patterns observed with digestive fluids, which corroborates our previous study that complexation by dissolved amino acids (AA) in digestive fluids leads to metal solubilization (Chen \& Mayer 1998b; Environ Sci Technol 32:770-778). The relative importance of the fast and slow reactions appears to depend on the ratio of ligands in gut fluids to the amount of bound metal in sediments. High ligand to solid metal ratios result in more metals released in fast reactions and thus higher lability of sedimentary metals. Multiple extractions of a sediment with digestive fluid of $A$. marina confirm the potential importance of incomplete reactions within a single deposit-feeding event, and make clear that bioavailability to a single animal is likely different from that to a community of organisms. The complex kinetic patterns lead to the counterintuitive prediction that toxification of digestive enzymes by solubilized metals will occur more readily in species that dissolve less metals.
\end{abstract}

KEY WORDS: Bioavailability · Sedimentary metals · Deposit feeders · Digestive fluid · Solubilization kinetics - Gut retention time · Dissolved amino acids

\section{INTRODUCTION}

Heavy metals can accumulate in marine organisms via uptake from external fluid phases or food ingestion (Harvey \& Luoma 1985a). Laboratory and modeling studies showed that the relative importance of the 2 pathways differs among metals with various biogeochemical behaviors (Harvey \& Luoma 1985a, Thomann et al. 1995, Fisher et al. 1996, Wang et al. 1996). In general, metals with higher affinity to sedimentary surfaces have a lower assimilation efficiency (Luoma \& Jenne 1977, Wang et al. 1996), suggesting the importance of solubilization in metal bioavailability. Separa-

•E-mail: lmayer@maine.maine.edu tion of metal exposure pathways via water and food, however, indicated that food items could be primary sources of bioaccumulation of $\mathrm{Zn}, \mathrm{Cd}, \mathrm{Cu}, \mathrm{Hg}, \mathrm{Pb}, \mathrm{Ni}$ (Thomann et al. 1995) and Ag (Harvey \& Luoma 1985b). The importance of this pathway was attributed to the greater metal concentrations in food items (e.g. seston and sediments), despite higher assimilation efficiency from fluid phases (Harvey \& Luoma 1985b). Thus metal solubilization from these food items is thought to be the first step for overall assimilation (Gagnon \& Fisher 1997), and any processes that enhance metal desorption/solubilization from solid phases may lead to a greater bioavailability (Chen 1997). The importance of food ingestion and digestion in bioavailability was well illustrated with in vitro digestion experiments by incubating digestive fluids of marine 
deposit feeders with Cu-contaminated sediments; digestive fluid released 2 to 3 orders of magnitude more sedimentary $\mathrm{Cu}$ than seawater controls (Mayer et al. 1996). A follow-up study showed that complexation of sedimentary $\mathrm{Cu}$ with amino acids (AA) in gut fluid was responsible for the marked dissolution, while the nearly neutral $\mathrm{pH}$ in gut fluids of these marine deposit feeders ruled out the possibility of an $\mathrm{H}^{+}$-mediated process (Chen \& Mayer 1998b). Although some of the solubilized metals may not be subsequently bioaccumulated, this process does expose guts to elevated concentrations of metals and can lead to digestive enzyme toxification (Chen \& Mayer 1998a). In addition, some amino acid-or peptide-metal complexes can be assimilated much more efficiently than inorganic metal species (Pecon \& Powell 1981, Ashmead 1991).

In the previous in vitro digestion experiments, we showed that the amounts of sedimentary $\mathrm{Cu}$ dissolved over a fixed period (i.e. $4 \mathrm{~h}$ ) varied among gut fluids of different species of organisms (Mayer et al. 1996, Chen \& Mayer 1998b). This species-specific variation correlated with luminal concentrations of AA (Chen 1997, Chen \& Mayer 1998b). In the present study, we focus on another factor with potential impact on the solubilization and bioavailability of sedimentary metals - the digestion time, or gut retention time (GRT) during in vivo digestion. GRT varies greatly among species of deposit feeders and is an important factor in their digestive capacities (Penry 1989). GRT correlates positively with increasing gut volume (and body size) among deposit feeders with tubular guts under a given diet quality (Penry \& Jumars 1990). Variation in food quality is an important factor leading to intraspecific variations in GRT (Cammen 1980, Taghon \& Jumars 1984, Taghon \& Greene 1990).

Our objectives, therefore, are (1) to determine the bioavailability of sedimentary metals $(\mathrm{Cu}, \mathrm{Cd}, \mathrm{Pb})$ within digestive constraints such as GRT and AA concentrations along gut sections of 3 benthic invertebrates, and (2) to reveal factors determining the kinetics of metal solubilization in guts. First, time-courses of sedimentary metal dissolution were observed by conducting in vitro digestion experiments of various sediment-organism combinations. Kinetics were then compared by quantifying reaction rates and apparent pool sizes of sedimentary metals, and were further analyzed based on the variation of gut AA and sedimentary metal concentrations. Solutions of bovine serum albumin (BSA) with different concentrations of AA were used to simulate gut fluid incubated with the same sediment. In addition, repeated extraction on the same sediment by fresh aliquots of gut fluid provided an ecotoxicological context. Finally, a conceptual model of metal solubilization in gut sections was set up based on the ligand concentrations along gut sections.

\section{METHODS AND MATERIALS}

In vitro digestion. Digestive fluid from the digestively intensive sections (midguts) of the polychaete Arenicola marina and the holothuroid Parastichopus californicus were extracted as in Mayer et al. (1996). These organisms were chosen because they could provide enough volume of digestive fluids for experiments and because of their large range of GRT, from $1-2 \mathrm{~h}$ (A. marina, McLeod 1994) to 5-9 h (P. californicus, Self et al. 1995). In addition, a suspension-feeding holothuroid (Cucumaria frondosa) was also selected to study the variation of metal bioavailability due to a different feeding mode, although experimental data on GRT of C. frondosa are unavailable at this time. Sediment particles were removed from gut fluid by centrifugation at $8000 \times g$ and $4{ }^{\circ} \mathrm{C}$ for $30 \mathrm{~min}$. Gut fluid from multiple individuals $(>10)$ of the 3 species were pooled and stored in $1.5 \mathrm{ml}$ plastic vials at $-80^{\circ} \mathrm{C}$ until experiments. Concentrations of total dissolved AA in gut fluid, an important parameter in metal remobilization (Chen \& Mayer 1998b), were analyzed by hydrolyzing samples in $6 \mathrm{~N} \mathrm{HCl}$, derivatizing the AA with orthophthaldialdehyde, and assaying fluorometrically using a Hitachi FL4500 fluorometer. This method typically yields results with coefficients of variation $<10 \%$

Contaminated sandy, surface $(5 \mathrm{~mm})$ sediments were collected in intertidal zones at Boothbay Harbor $(\mathrm{BH})$, Maine, USA (total $\mathrm{Cu}, \mathrm{Pb}$ and $\mathrm{Cd}$ concentrations $\approx$ 1114, 186 and 0.33 ppm), and Portsmouth Harbor (PH1, $\mathrm{PH} 2$ ), New Hampshire, USA (total $\mathrm{Cu}, \mathrm{Pb}$ and $\mathrm{Cd}$ concentrations $\approx 182,74$ and 0.14 ppm for $\mathrm{PH} 1$; and 204 , 88 and 0.08 ppm for PH2). Excess copper and lead in sediments presumably originated from nearby shipyard activities. Total sedimentary metal concentrations were measured by a graphite furnace atomic absorption spectrophotometer (GFAAS) with an ultrasonic slurry sampler as in Mayer et al. (1996), and the methods were certified with the standards MESS-1 and BCSS-1

For in vitro digestion experiments, sediments were first centrifuged to remove most of their original pore water. Sediments (about $0.2 \mathrm{~g}$ wet weight, 3 replicates) were then incubated with $500 \mu$ l digestive fluid or seawater (as a control, collected from the Damariscotta Estuary, Maine). The mixtures were then held at room temperature on a shaker either for a fixed period of $4 \mathrm{~h}$ or for a period of 2 to $360 \mathrm{~min}$ during kinetic experiments. Controls also included digestive fluid without sediment. During the kinetic experiments, incubations were stopped periodically by centrifugation at $8000 \times g$ for $30 \mathrm{~min}$ at $4^{\circ} \mathrm{C}$. Metal contents in fluids were measured by GFAAS with a coefficient of variation $<5 \%$ (Chen \& Mayer 1998b). Final metal concentrations in 
gut fluid after incubation were corrected by subtracting those in seawater, assuming that seawater releases only metals associated with pore water or loosely adsorbed fractions. Thus the final concentrations represent the amounts of metal dissolved by digestive agents alone.

BSA (bovine serum albumin) incubation. Because dissolved gut A.A plays an important role in solubilization of sedimentary Cu (Chen \& Mayer 1998b), we used solutions of the protein BSA (Sigma P6529), with varying $\mathrm{AA}$ concentrations, to mimic the in vitro digestion experiments with digestive fluids of the 3 studied species and the sediment PH1. The BSA experiments thus provide insights on the effects of AA concentration alone on the kinetics of metal solubilization. Concentrated BSA solutions were diluted with $0.85 \% \mathrm{NaCl}$ (the media in concentrated BSA stocks) to achieve BSA solutions with 8.3, 333 and 1667 mM AA, encompassing the range of $A A$ concentrations of gut fluid found by Mayer et al. (1997). No contamination of metals was found in the $0.85 \% \mathrm{NaCl}$ solution, which was used as a control fluid for the BSA experiments.

Processing of kinetics data. Metal concentrations in the $500 \mu$ incubation fluids were divided by the dry weight of respective sediments to reduce variation due to differences in weight of sediment $(\leq 13.5 \%$ for same sediments and $\leq 20 \%$ among sediments). Data from this treatment thus represent metal concentrations $(\mu \mathrm{M})$ in an incubation experiment at a fluid: dry sediment ratio of $500 \mu \mathrm{l}$ to $1 \mathrm{~g}$

Most of the data clearly showed a biphasic reaction, including a fast and a slow portion, which cannot be modeled with a single, conventional kinetic expression. A combination of 2 first-order reactions, however, could generally simulate the observed data:

$[M]=m 0-m 1 \times \exp (-K 1 \times t)-m 2 \times \exp (-K 2 \times t)$

where $[M]$ is the net amount of metal in gut fluid or BSA solutions at $t$ (incubation time), $m 0$ is the asymptotic value of total remobilizable metal in sediments, $m 1$ and $K 1$ are the asymptotic amount and rate constant of the quickly transferred metal, and $m 2$ and $K 2$ are those of the slowly transferred metal. A computer program, KaleidaGraph, was used to curve-fit the metal concentrations from all kinetics experiments and yielded values for $m$ and $K$. Essentially, we assign the total solubilized metals into 2 phases with Eq. (1): an F-transfer (the 2nd term) being released quickly and an S-transfer being released or re-adsorbed (i.e. back reactions) slowly (the 3 rd term). The initial rate of sedimentary metal transferred to solution, or its lability, is expressed as ( $m 1 K 1+m 2 K 2)$. Data without clear kinetic trends or showing no release (i.e. Fig. $1 \mathrm{~g}-\mathrm{i}$, $q-r)$ are not considered. Rate constants (always $\geq 0$ ) thus describe the apparent rate of approach to equilib- rium or steady state assuming first-order kinetics. A positive transfer $(m 0=m 1+m 2)$ is the amount of sedimentary metals released during the time-course, and the amount of gut metals lost during re-adsorption (only during slow reactions) yields a negative $m 2$. Although these biphasic kinetic data could be curvefitted with a variety of algebraic expressions, the format of Eq. (1) allows us to focus on quantitative comparison of kinetics among various gut fluid-sediment combinations. Thus we intend to deduce neither the exact order nor the explicit expression of a reaction; rather, Eq. (1) is a convenient way to measure the extent of the total projected metal $(m 0)$ being released by the 2 reactions expressed by $F$ - and S-transfers. Similarly, the rate 'constants' ( $K 1 \& K 2$ ) should be used only descriptively, because they may depend highly on both the experimental conditions and the method of data fitting. For example, rate constants for the F-transfer (K1) were essentially determined by 1 or 2 initial data points. Their values are therefore controlled by the timing of the first sampling, and hence $K 1 \geq$ the value shown.

$\mathrm{Cu}, \mathrm{AA}$ and digestive enzymes along gut sections. In order to compare the kinetic data from incubation experiments with in vivo distributions along gut sections (i.e. foregut, midgut, mid-hindgut and hindgut),

Table $1 \mathrm{Cu}$ concentrations ( $\mu \mathrm{mol} \mathrm{l^{-1 }}$ gut fluid, \pm 1 analytical $\mathrm{SD})$, dissolved amino acids (A.A, $\mu$ mol $\mathrm{l}^{-1}$ gut fluid) and enzyme activities ( $\mu \mathrm{M}$ substrate hydrolyzed $\mathrm{min}^{-1}$ ) along gut sections of 4 species of deposit and suspension feeders. Specimens were collected from Puget Sound, Washington, USA Information on sampling, taxon and feeding mode in parentheses (I: intertidal, P: polychaete, $\mathrm{H}$ : holothuroid, SFC-DPF: surface deposit feeder, FF: suspension feeder, ND: not determined)

\begin{tabular}{|c|c|c|c|c|}
\hline & $\mathrm{Cu}(\mu \mathrm{M})$ & $\mathrm{AA}$ & Protease & Esterase \\
\hline \multicolumn{5}{|c|}{ Eupolymnia heterobranchia (I, P, SFC-DPF) } \\
\hline Foregut & $4.53 \pm 0.49$ & 438 & 5500 & 34.8 \\
\hline Midgut & $5.79 \pm 0.85$ & 179 & 676 & 47.7 \\
\hline Mid/hind & $13.39 \pm 0.09$ & 42 & 110 & 81.0 \\
\hline Hindgut & $0.63 \pm 0.35$ & 32 & 0.4 & 4.3 \\
\hline \multicolumn{5}{|c|}{ Leptosynapta clarki (I, H, SFC-DPF) } \\
\hline Foregut & $1.10 \pm 0.15$ & 44 & 0.5 & 16.9 \\
\hline Midgut & $1.02 \pm 0.01$ & 33 & 1.9 & 34.1 \\
\hline Mid/hind & $1.12 \pm 0.08$ & 26 & 0.2 & 1.9 \\
\hline Hindgut & $0.09 \pm 0.02$ & 3 & 0.0 & 0.0 \\
\hline \multicolumn{5}{|c|}{ Schizobranchia insignis $(\mathrm{I}, \mathrm{P}, \mathrm{FF})$} \\
\hline Foregut & $1.26 \pm 0.08$ & 23 & 48.1 & 16.3 \\
\hline Midgut & $2.30 \pm 0.52$ & 43 & 215 & 55.8 \\
\hline Mid/hind & $4.71 \pm 0.07$ & 45 & 233 & 60.3 \\
\hline Hindgut & $0.55 \pm 0.03$ & 29 & 11.7 & 2.7 \\
\hline \multicolumn{5}{|c|}{ Cucumaria miniata $(\mathrm{I}, \mathrm{H}, \mathrm{FF})$} \\
\hline Foregut & $0.68 \pm 0.02$ & ND & 1.8 & 2.0 \\
\hline Midgut & $2.80 \pm 0.60$ & ND & 3.5 & 11.5 \\
\hline Mid/hind & $4.14 \pm 0.41$ & ND & ND & ND \\
\hline Hindgut & $1.72 \pm 0.59$ & ND & 0.0 & 10.8 \\
\hline
\end{tabular}



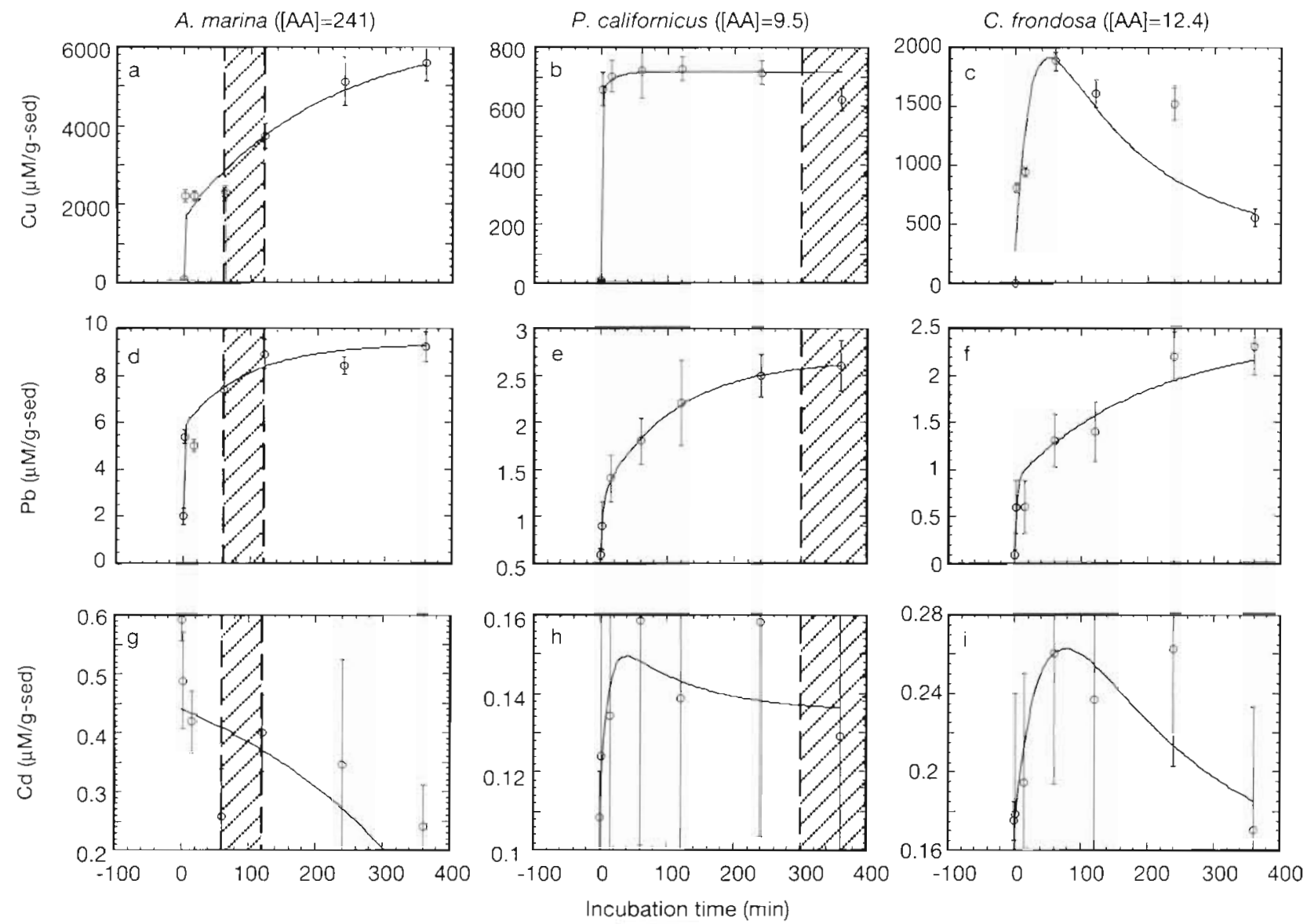

$\rightarrow \mathrm{BH}$

Fig. 1. Arenicola marina, Parastichopus californicus, Cucumaria frondosa. Sedimentary $\mathrm{Cu}(\mathrm{a}-\mathrm{c}, \mathrm{j}-\mathrm{l}), \mathrm{Pb}(\mathrm{d}-\mathrm{f}, \mathrm{m}-\mathrm{o})$ and $\mathrm{Cd}(\mathrm{g}-\mathrm{i}$, $\mathrm{p}-\mathrm{r}$ ) ( $\mu$ mol $\mathrm{l}^{-1}$ gut fluid $\mathrm{g}^{-1}$ sediment) remobilized by digestive fluids from sediments from $\mathrm{BH}(\mathrm{O}), \mathrm{PH}$, (a), and PH2 (a). Connecting lines show curve-fitting results $(n=3, \pm 1 \mathrm{SD})$; hatched areas gut retention time (GRT) and numbers in parentheses concentrations of amino acids $(\mathrm{mM})$ in gut fluid

we analyzed $\mathrm{Cu}$ concentrations by GFAAS on a set of gut fluids remaining from a previous study (Mayer et al. 1997), for which A.A concentrations and enzyme activities were known. The set of gut fluids included those from 1 individual each of 4 species, the polychaetes Eupolymnia heterobranchia and Schizobranchia insignis and the holothuroids Leptosynapta clarki and Cucumaria miniata (Table 1).

Multiple extractions. $1 \mathrm{ml}$ gut fluid of Arenicola marina was incubated with $0.4 \mathrm{~g}$ wet $\mathrm{BH}$ sediment $(3$ replicates) for $4 \mathrm{~h}$ and subsequently removed by centrifugation at $8000 \times g$ and $4^{\circ} \mathrm{C}$ for 30 min. A fresh aliquot of gut fluid was then added to the sediment to repeat the extraction; this sequence was carried out a total of 7 times to mimic a scenario of this plug of sediment being processed by 7 individuals of $A$. marina. Copper and lead concentrations in each aliquot of gut fluid were measured by GFAAS.

\section{RESULTS AND DISCUSSION}

\section{Digestive kinetics}

In experiments with sediment $\mathrm{BH}, \mathrm{Cu}$ concentrations in digestive fluid of Arenicola marina, Parastichopus californicus and Cucumaria frondosa increased rapidly, followed by either a gradual increase or decline (Fig. $1 \mathrm{a}-\mathrm{C}, \mathrm{j}-\mathrm{l}$ ). The leveling in $\mathrm{Cu}$ concentrations toward the end of the incubation suggests limitation of one of the reactants - Cu-binding ligands in gut fluid or remobilizable $\mathrm{Cu}$ in sediments. Declines, or back reactions, were often observed in experiments using $C$. frondosa gut fluid (Fig, 1C, l), presumably because of re-adsorption of $\mathrm{Cu}$, perhaps as $\mathrm{Cu}$-protein complexes, onto sediments. Back reactions may have occurred in all of the experiments, but the effects might have been below the detection limit in some experiments (e.g. 

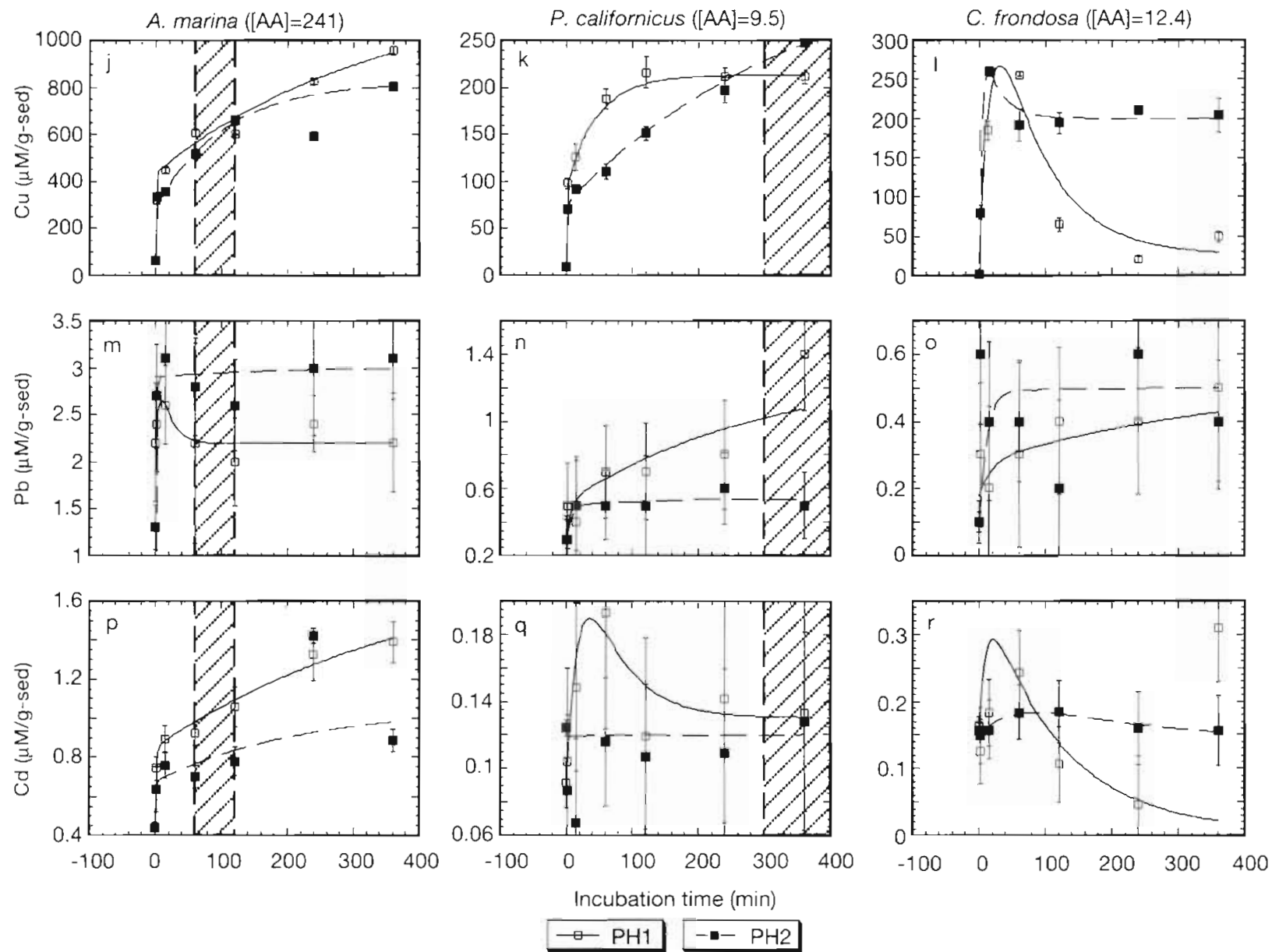

Fig. $1 \mathrm{a}, \mathrm{b})$. The patterns of $\mathrm{Pb}$ remobilization resembled those of $\mathrm{Cu}$, but its kinetics were less clear in 2 C. frondosa experiments due to variance in the data (Fig. 10). Similarly, no clear kinetics can be observed from the $\mathrm{Cd}$ data in experiments of $P$. californicus and C. frondosa (Fig. 1h-i, q-r), presumably because of the low Cd contents in the sediments (see 'Methods and materials').

These time-course experiments indicated that the amounts of metal released, which presumably would be available to the digestive systems of deposit feeders, depend on incubation time. Thus deposit feeders with different GRT but similar ligand concentrations may be exposed to different amounts of heavy metals even if they ingest the same sediment. F-transfer metals were generally solubilized well within the GRT of all 3 species (Fig. 1). Reactions involving S-transfer metals varied among organisms and metals. In Arenicola marina experiments, the release of S-transfer $\mathrm{Cu}$ and $\mathrm{Cd}$ did not complete within its GRT, so that more would be released if its GRT were longer (Fig. 1a, g, $j, \mathrm{p}$ ), but the $\mathrm{Pb}$ reaction was close to completion. In contrast, all S-transfer metals in Parastichopus califor- nicus experiments were near completion at time scales similar to its GRT (Fig. 1b, e, k, n). In Cucumaria frondosa experiments, back reactions were associated with all $\mathrm{Cu}$ kinetics (Fig. 1c, 1), but $\mathrm{Pb}$ reactions were positive and near completion (Fig. 1f, o).

Time-courses and the degrees of completion within GRT were functions of fluid types (i.e. animal species), sediments and metals. Because dissolved gut $\mathrm{AA}$ are the primary agents responsible for Cu release (Chen \& Mayer 1998b), variations of $\mathrm{Cu}$ release kinetics in the present study can be interpreted by comparing concentrations of AA among gut fluids (Fig, 1). When AA concentrations were high, as with Arenicola marina, both fast and slow reactions were observed. In Parastichopus californicus (with low AA), Cu-binding ligands could be quickly saturated, and thus slow reactions were less pronounced (Fig. 1). Although little information is available on the identities of $\mathrm{Cd}$ - and $\mathrm{Pb}$ binding agents in gut fluids, ongoing studies indicate that they differ from that of the Cu-binding agent (Chen \& Mayer unpubl. data). Lower ligand concentrations or sedimentary loading may account for the smaller magnitudes of transfer and near completion of 
$\mathrm{Pb}$ reactions, but the former factor seems more likely because more $\mathrm{Pb}$ was released when additional ligand was added (see following section). Metal kinetics apparently differed among the sediments (Fig. 1), which cannot be explained solely by the variations of sedimentary metal loading and suggests the importance of interactions between gut fluid and sediment.

Strong back reactions in gut fluid of Cucumaria frondosa (Fig. 1C, l) and Arenicola marina (Fig. 1g, m) may be derived from the formation of surface-reactive, metal-ligand complexes. Elliott \& Huang (1979, 1980, 1981) and Baffi et al. (1994) indicated that the formation of metal-AA complexes could either enhance or reduce adsorption of metals and ligands. The significance of this effect can be influenced by the ratio of ligand to metal, which determines the sign of charges of the complex species and thus the mechanisms of their adsorption (Elliott \& Huang 1979). For example, neutral metal-AA complexes may behave more like organic molecules and adsorb onto solid phases via hydrophobic interactions, while charged metal-AA complexes may interact electrostatically with the solid surface. Metal binding may also bridge 2 or more ligand molecules and increase the size of the complex, which could lead to precipitation. Furthermore, a fraction of the released metals may associate with ligands of very large molecular weight (e.g. proteins), which could be destabilized in an aqueous environment due to metal-induced loss of hydrophilic-hydrophobic balance. This last possibility exists at least in $A$. marina gut fluid, in which significant amounts of $\mathrm{Cu}$ and $\mathrm{Cd}$ were associated with ligands with molecular weights $>100 \mathrm{kDa}$ (Chen 1997).

Low Cd loading in these sediments in comparison to $\mathrm{Cu}$ and $\mathrm{Pb}$ (see 'Methods and materials') not only led to less net release but also led to net adsorption of $\mathrm{Cd}$ already dissolved in the original gut fluid (e.g. Fig. 1g). For any given ligand, the sediment surface serves as a potential adsorbent for metal-ligand complexes. Net release of Cd will occur only if sufficient sedimentary Cd complexes to an amount of dissolved ligands that exceeds the loss of Cd-ligand complexes to adsorption. This principle was demonstrated with the BSA experiment, in which the ligand type was held constant but its concentration varied (Fig. 2c). Low BSA (8.3 mM AA) solution solubilized a small amount of sedimentary $\mathrm{Cd}$, which subsequently was lost to binding sites in sediments as Cd-BSA complexes.

Cucumaria frondosa showed the greatest susceptibility to back reactions (Fig. 1c, I), which probably is due to the fact that $C$. frondosa is primarily a suspension feeder (Jordan 1972), and the experimental conditions may be unrealistic of in vivo conditions. Its digestive enzymes are not accustomed to large quantities of inorganic surfaces, perhaps making it susceptible to net adsorption of gut ligands. Previous physiological data showed that gut fluids of suspension feeders (including $C$. frondosa) have less surfactancy (i.e. no micelles) than their deposit-feeding counterparts (including Parastichopus californicus, Mayer et al. 1997). Because surfactants enhance the solubility of hydrophobic organic materials considerably (Diallo et al. 1994), lack of surfactancy in gut fluid of C. frondosa may explain the frequent occurrence of back reactions in experiments on this species
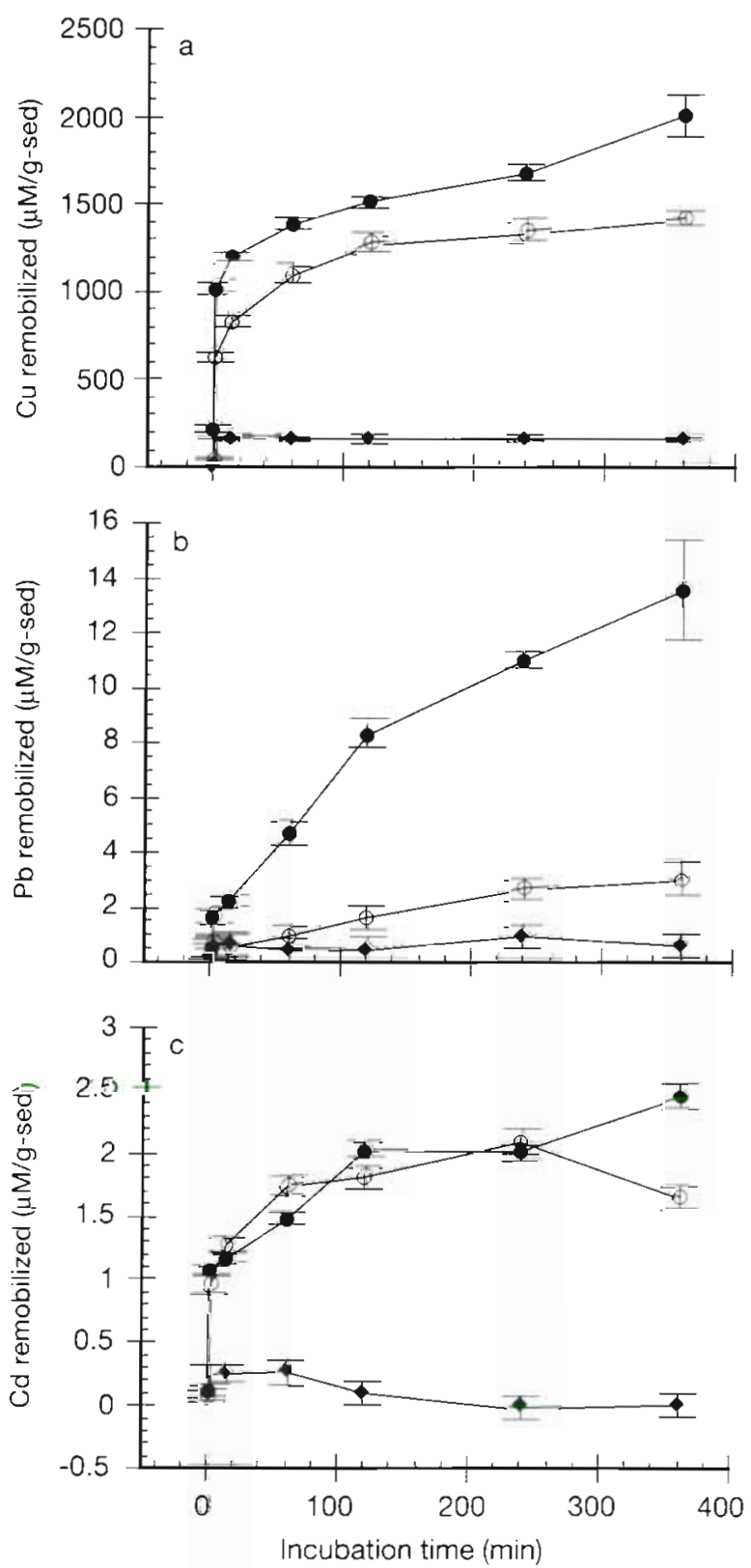

Fig. 2. Kinetics of $\mathrm{Cu}(\mathrm{a}), \mathrm{Pb}(\mathrm{b})$ and $\mathrm{Cd}$ (c) ( $\mu \mathrm{mol} \mathrm{l}^{-1} \mathrm{BSA} \mathrm{g}^{-1}$ sediment) remobilized from sediment $\mathrm{PH} 1$ by solutions of bovine serum albumin (BSA) with various AA concentrations: $1667(\bullet), 333(0), 8.3(\bullet) \mathrm{mM}$ 
Fig. 3. Arenicola marina (AM), Parastichopus californicus (PC). Cucumaria frondosa (CF). Asymptotic values of fast (grey bar) and slow (open bar) pools of metal released $(>0)$ or adsorbed $(<0)$ in experiments shown in Figs. 1 \& 2, as calculated by curve-fitting based on Eq. (1). Values in $\mu$ mol $\mathrm{l}^{-1}$ gut fluid $\mathrm{g}^{-1}$ sediment for $\mathrm{Cu}(\mathrm{a}, \mathrm{d}, \mathrm{g}), \mathrm{Pb}(\mathrm{b}$, $e, h)$ and $C d(c, f, i)$, and for sediment $\mathrm{BH}(\mathrm{a}-\mathrm{c}), \mathrm{PH} 1$ $(d-f)$ and $\mathrm{PH} 2$ (g-i). Numbers below columns are amino acid (AA) concentrations (mM). Starred columns (Cd) indicate kinetic data with high variance
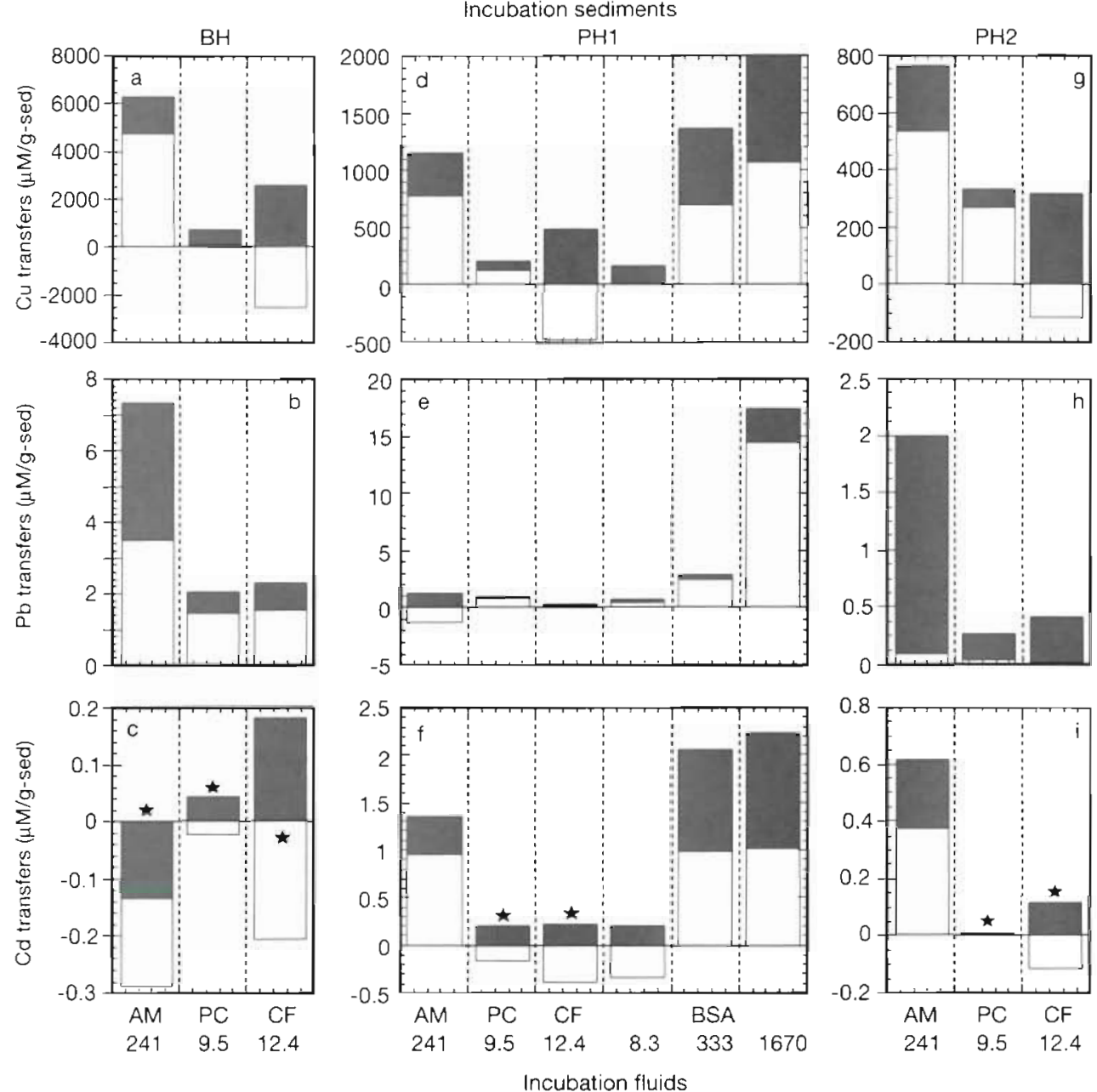

\section{BSA kinetics}

BSA experiments allowed us to test for variation in kinetic patterns due to ligand concentration alone. Similar metal remobilization patterns were found as in those involving gut fluid with the same sediment (Fig. 2 vs Fig. 1). In agreement with gut fluid incubations, increasing BSA concentrations led to more metal remobilization (Figs. $2 \& 3 \mathrm{~d}-\mathrm{f}$ ). However, increases in total amounts of transfer were clearly not linearly proportional to the increase in BSA concentrations (Fig. 3d-f; Chen \& Mayer 1998b), which may result from limited sedimentary metals (e.g. Cd in Figs. 2c \& 3f; Chen \& Mayer 1998b). Consistent with gut fluid incubation, high BSA concentrations produced clearly biphasic time-courses (Figs. $2 \& 3 d-f$ ). In experiments at low BSA concentrations, F-transfer metals accounted for a larger proportion of the total with a second reaction that was small, absent, or negative (Fig. 2). Except for $\mathrm{Cd}$, which was limited in sedimentary loading (Fig. 3f), increasing BSA concen-

trations led to increases in both fast and slow transfers (Fig. 3d, e), indicating that for a given collection of ligands, total bioavailable metals (i.e. F- plus S-transfers) in this sediment vary with total ligand concentrations. BSA at similar AA concentrations removed more $\mathrm{Pb}$ than did gut fluids of Arenicola marina (Fig. 3e), which suggests that the sizes of bioavailable pools also varied with the types of interacting ligands and perhaps the number of $\mathrm{Pb}$-binding sites per mole AA. Therefore, AA concentration is not as predictive for $\mathrm{Pb}$ remobilization as for $\mathrm{Cu}$ and $\mathrm{Cd}$ (Fig. 3d, $\mathrm{f}_{\text {; }}$ Chen \& Mayer 1998b), which may be due to differences in the proportion of $\mathrm{Pb}$-binding sites between gut fluids and BSA.

\section{Rate constants and sedimentary metal lability}

Rate constants of the F-transfers (K1) were generally at least 1 or 2 orders of magnitude higher than those of the S-transfers (K2), except for experiments 
Table 2. Lability of $\mathrm{Cu}, \mathrm{Pb}$, and $\mathrm{Cd}\left(\mu \mathrm{Mg}^{-1}\right.$ sediment $\mathrm{min}^{-1}$, in italics) in sediments from $\mathrm{BH}, \mathrm{PH} 1$ and $\mathrm{PH} 2$ and rate constants of $F$ - and $S$-transfers ( $K 1$ and $K 2$, min $i$ (in parentheses) derived from the incubation experiments (Fig. 1) with digestive fluid of Arenicola marina, Parastichopus californicus, Cucumaria frondosa and solutions of bovine serum. albumin (BSA) of varying concentrations. Dissolved amino acid (AA) concentrations (mM) are listed below the fluid type. Blank cells: no data available; $\cdot$ data not considered due to large data variance

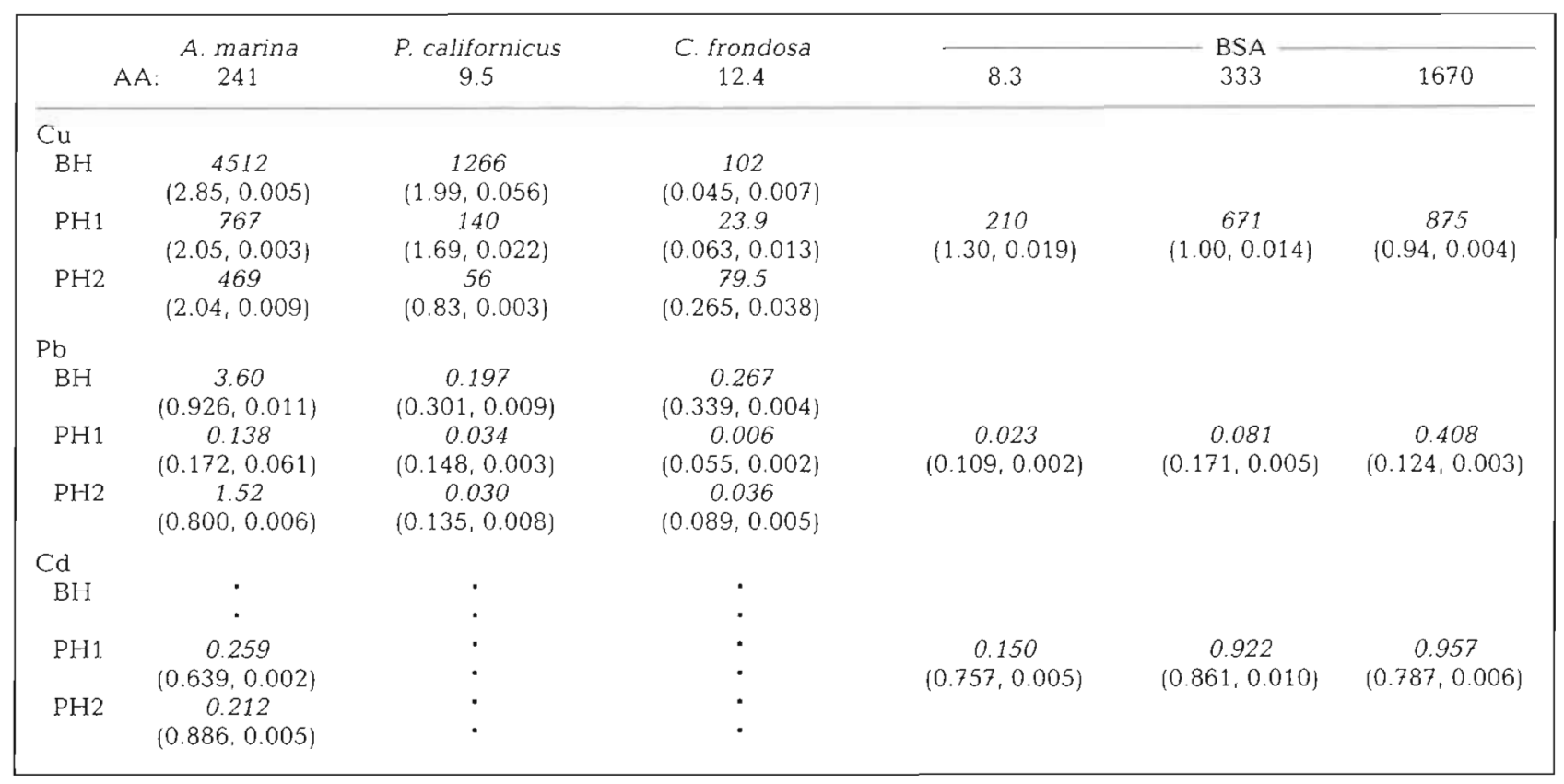

in which back reactions became important (Table 2). Rate constants in BSA experiments were in the same range as in gut fluid experiments. The narrower variation in $K$-values over a large range of BSA concentrations, as contrasted to larger variations in gut fluid experiments on the same sediment or among sediments (Table 2), suggests that the $K$-values depend not simply on the AA concentration in gut fluid, but also on fluid type (i.e. species of organism) and sediments.

Sedimentary metal lability ( $m 1 K 1+m 2 K 2$ ), defined as the initial rate of metal transfer to digestive fluids, provides a time-based parameterization of metal bioavailability to digestive attack. Because $K 1 \gg K 2$ in all of the experiments, the term $m 1 K 1$, which corresponds to F-transfers, determined the magnitude of lability in each sediment-organism combination. Higher lability in sedimentary metals may damage the digestive system of deposit feeders (Chen \& Mayer 1998a). Cu lability was the highest among the metals in the sediments (Table 2), which is largely due to the sedimentary $\mathrm{Cu}$ concentrations being higher than those of $\mathrm{Pb}$ and $\mathrm{Cd}$. Similarly, sediment $\mathrm{BH}$, which was heavily contaminated with $\mathrm{Cu}$ and $\mathrm{Pb}$, had the highest labilities among the sediments. The rank of metal lability for the same sediments among gut fluids and BSA solutions was generally consistent with the rank of AA concentrations (Table 2). Thus the combination of large sedimentary metal loading and elevated concentrations of gut AA leads to higher lability. However, metal lability of the same sediment also depended on the fluid types (i.e. species of organisms), as indicated by the inconsistencies between BSA and gut fluids of similar AA concentrations.

Kinetic patterns observed in this study indicated that metal bioavailability in a given sediment-gut fluid combination may derive from a fast and, sometimes, a slow reaction. The magnitudes and relative importance of the F-and S-transfers, and thus the total bioavailable pool within the incubation time frame, did not appear to be a simple function of any individual component in the reactions, but rather a result of an interaction between gut ligands and sedimentary metals. Varying kinetics among metals for a given gut fluid-sediment combination, on the other hand, were likely derived from the specificity of metal-binding ligands or due to the contribution from varying solid chemistry. For example, the amino acid histidine is responsible for the bulk of $\mathrm{Cu}$ solubilization (Chen \& Mayer 1998b), while another kind of amino acid or a different combination of binding sites might determine $\mathrm{Pb}$ solubilization. Results from gut fluid and BSA experiments (Figs. 1 \& 2) suggest that variations in the mole ratio of ligand to metal-loading in an incubation experiment were also critical in determining the pattern of kinetics. Under a low AA to sedimentary $\mathrm{Cu}$ 
ratio of $9: 1$ (given $[\mathrm{AA}]=8.3 \mathrm{mM}$ in $500 \mu \mathrm{BSA}$ and $[\mathrm{Cu}]=182 \mathrm{\mu g} \mathrm{g}^{-1}$ in $0.16 \mathrm{~g}$ dry sediment PH1, Fig. 2a), the solubilization of $\mathrm{Cu}$ was primarily limited by the ligand pool; a relatively small amount of the sedimentary Cu was released, and this release was dominated by F-transfer ( $\leq 2 \mathrm{~min})$. Increasing ratios of $\mathrm{AA}: \mathrm{Cu}$ loading to $363: 1$ ([AA] $=333 \mathrm{mM}$ ) and further to $1820: 1$ $([\mathrm{AA}]=1667 \mathrm{mM})$ led to more $\mathrm{Cu}$ operationally being defined as F-transfer ( $\leq 2 \mathrm{~min}$ ), and the appearance of significant S-transfer (Figs. 2a \& 3d). The increase of both $\mathrm{F}$ - and $\mathrm{S}$-transfer when the A.A:Cu-loading ratios increased from 363:1 to 1820:1 (Fig. 3d) cannot be explained by the existence of 2 distinct pools of sedimentary $\mathrm{Cu}$, otherwise there would have been an identical amount of F-transfer and an increasing S-transfer with increasing AA concentrations. Thus F- and S-transfers may not necessarily represent metals derived from 2 distinct sedimentary pools, but instead result from a sequence of reactions ranging from extremely rapid to completely inert (i.e. non-reactive during the experimental time frame). The lability of sedimentary metals, operationally defined as the rate of transfer to gut ligands, is clearly a function of the varying reactivity of gut ligands; in other words, the reactivity of gut ligands makes sedimentary metal labile.

Variation in the lability of sedimentary metals (i.e. the initial rate of transfer: $m 1 K 1+m 2 K 2$ ) may have both a thermodynamic and a kinetic basis. Sedimentary metals are probably bound to a spectrum of strong to weak solid-phase ligands (Luoma \& Jenne 1977), as suggested by varying metal affinities towards different competing components in sediment (Calmano et al. 1988). The fact that only a small fraction of sedimentary metals was solubilized (Mayer et al. 1996) within a wide range of incubation times (Figs. 1 \& 2) corroborates the concept of variable metal-binding strength in sediments. Similarly, dissolved gut ligands also harbor a spectrum of strong to weak metal-binding sites, and only a fraction of binding sites are sufficiently strong to participate in metal solubilization (Chen \& Mayer $1998 b)$. The ' $m$ ' terms in the lability components are apparently controlled by the difference in free-energy states between the sedimentary and gut ligands, because increasing dissolved ligands relative to given amount of sediment resulted in higher metal solubilization (Fig. 3d-f). An important implication is that the magnitude of $m 1$ or $m 2$ might be limited by the amount of ligands of a threshold binding strength either in solution or on the solid phase (see 'Multiple extraction' section). Variations either in accessibility (e.g. diffusion) of metals through a sedimentary matrix or in activation energy of reactions likely control the ' $K$ ' terms of lability, although our experimental approach does not allow us to specify the processes responsible for variations in $K$. This analysis strongly suggests that the bioavailability of sedimentary metal is not a capacity of either sediments or species of organisms alone. Rather, it should be viewed as a product of organism-sediment interactions.

\section{Multiple extraction}

Total remobilizable $\mathrm{Cu}$ in the sediments declined rapidly after the first incubation cycle and then slowly decreased further over the remaining 6 cycles (Fig. 4a). Because the experiment provided additional ligands in each subsequent incubation, smaller release during the last few cycles suggests that labile sedimentary $\mathrm{Cu}$ was limited, which is consistent with the conceptual model above in that each aliquot of digestive fluid sequentially removed the most-labile $\mathrm{Cu}$ remaining in the sediment. Each digestive cycle represented a $4 \mathrm{~h}$ experiment, so that the $x$-axis could be viewed as an extended time for in vitro incubation. Fig. $4 \mathrm{a}$ thus essentially shows a 'fast transfer' within the first $4 \mathrm{~h}$, followed by a small 'slow transfer' lasting an additional $24 \mathrm{~h}$, corroborating the biphasic kinetics in a normal in vitro digestion (Fig. 1a). This experiment could also be viewed as an ecotoxicological extension of individual toxicokinetics, in which a plug of sedi-

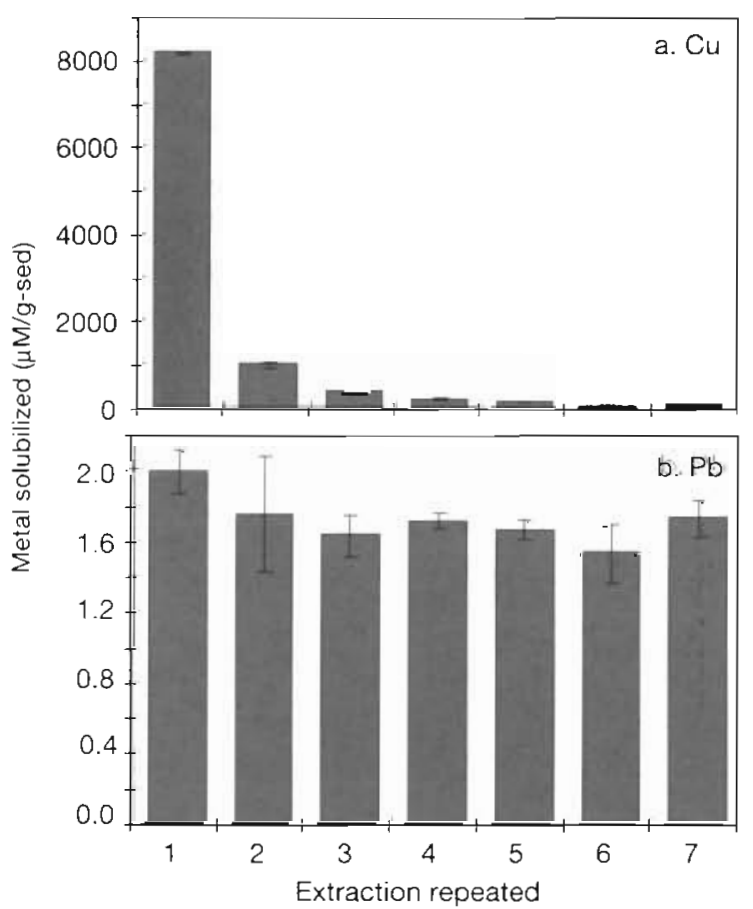

Fig. 4. Arenicola marina. Contaminated $\mathrm{Cu}(\mathrm{a})$ and $\mathrm{Pb}$ (b) $\left(\mu \mathrm{mol} \mathrm{l}^{-1}\right.$ gut fluid $\mathrm{g}^{-1}$ sediment; $\pm 1 \mathrm{SD} ; \mathrm{n}=3$ ) solubilized by 7 aliquots of the digestive fluids incubated sequentially with the same sediment sample (BH) 
ments went through 7 Arenicola marina guts with highest $\mathrm{Cu}$ exposure in the first gut. Assuming that kinetics in the first digestion cycle resembled that in Fig. 1a (i.e. $80 \%$ completion within 4 h), the amount of $\mathrm{Cu}$ dissolved in the second cycle can be predicted by calculating the uncompleted part of the S-pool in the previous cycle. This calculated value is within a factor of 2 of the observed release, suggesting that most of the $\mathrm{Cu}$ released after the first cycle was probably the continuation of the slow reaction in Fig. 1a. This behavior is also an indication of solid phase $\mathrm{Cu}$ limitation in spite of a continuous supply of fresh digestive fluid.

The remobilization of $\mathrm{Pb}$ differed greatly from that of $\mathrm{Cu}$ in that a roughly constant amount of $\mathrm{Pb}$ was released during each digestive cycle, suggesting saturation of $\mathrm{Pb}$-binding ligands in each of the 7 aliquots of gut fluids (Fig. 4b). Incubation of sediment BH with solutions of another commercial protein (casein) of similar A.A concentration, on the other hand, removed 1 order of magnitude more $\mathrm{Pb}$ than the gut fluids (data not shown), which corroborates the hypothesis that low concentrations of Pb-binding ligands in gut fluid were the limiting factors in $\mathrm{Pb}$ solubilization. However, the biphasic kinetic data in Fig, 1d showed $90 \%$ completion within the first $4 \mathrm{~h}$ of incubation and thus provided no hint that a similar amount of $\mathrm{Pb}$ would be dissolved in the second cycle. Therefore, the behavioral difference between $\mathrm{Cu}$ and $\mathrm{Pb}$ reveals an important ecotoxicological implication. similar kinetics within the first gut passage does not necessarily result from a similar solubilization mechanism (i.e. solid-phase limitation for $\mathrm{Cu}$ vs ligand limitation for $\mathrm{Pb}$ ).

\section{Solubilization during gut passage}

What is the time-course of dissolution when sedimentary grains are subjected to in vivo digestion by a deposit feeder? The guts of many deposit feeders are tubular, with 3 or 4 morphologically distinct sections: foregut, midgut, mid-hindgut and hindgut (Penry \& Jumars 1990). Although the functional differences among these gut sections are still under investigation, literature data suggest that higher extracellular enzyme activity (Mayer et al. 1997) and absorption (Kaganovskaya 1983, Self et al. 1995) both occur in gut sections with enlarged surface area in the form of epithelial folding (Sampson et al. unpubl. data), such as the midgut to mid-hindgut of Arenicola marina and foregut to midgut of Parastichopus californicus. High AA concentrations are often associated with high enzymatic activity around the midgut region, making this area an intensive zone of digestion, while lower values are found in the posterior gut (Mayer et al. 1997). This pattern of AA distribution, coupled to the time-courses of in vitro digestion (Figs. 1 \& 3), suggests varying patterns of metal remobilization along the guts, in terms of fast and/or slow reactions.

A conceptual model of $\mathrm{Cu}$ solubilization is proposed (Fig. 5) for a plug of contaminated sediment moving through the gut of an Arenicola marina or a Parastichopus californicus, in which the relative geometry of gut sections is adapted from Sampson et al. (unpubl. data). We examine these 2 deposit feeders because their guts represent 2 contrasting types of digestive strategies, with stronger digestive activities (e.g. high enzyme activity and AA concentration) in guts of shorter GRT (i.e. A. marina) and weaker digestive activities in guts of longer GRT (i.e. $P$. californicus). The AA profile along the gut was derived from only 3 or 4 data points in Mayer et al. (1997), and thus does not necessarily represent the actual, continuous AA distribution along the gut. Under such a simplified assumption, the 2 species' anterior gut sections can be viewed as different reaction chambers with gut fluids

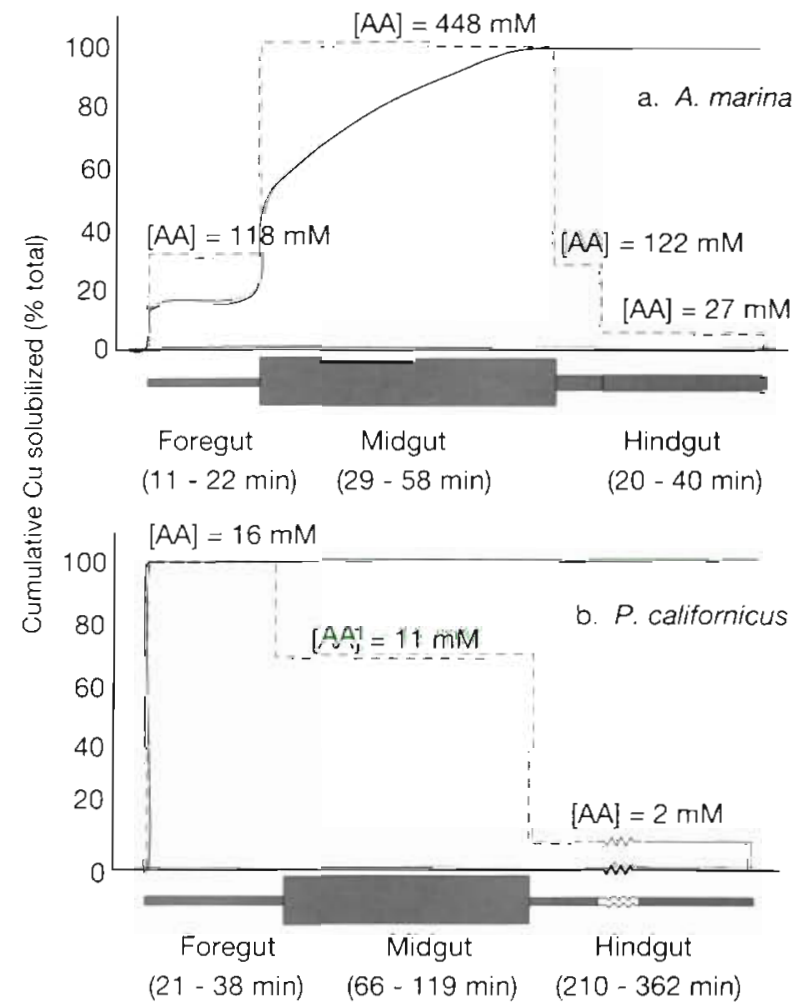

Fig. 5. (a) Arenicola marina: a high $A_{A}$, short GRT (1 to $2 \mathrm{~h}$ ) gut; (b) Parastichopus californicus: a low AA, long GRT (5 to 9 h) gut. Conceptual models of total Cu solubilized (-) from a plug of sediment during in vivo digestion driven by profiles of gut AA (- . . Mayer et al. 1997) among foreguts and midguts where active digestion occurs. Below the $x$-axis are the times sediment plugs spend in each gut section, estimated from GRTs and section length (Sampson et aI. unpubl. data) 
of different AA concentrations. In A. marina, the anterior sections would be exposed to only a fraction of available $\mathrm{Cu}$ in the form of the F-transfer (e.g. Fig. 1b) because of low AA concentrations, by analogy with the low [BSA] (Fig. 2a). A biphasic reaction (e.g. Fig. 1a) would be expected in the midgut region containing high concentrations of ligands, while $\mathrm{Cu}$ dissolution in the hindgut could be a very reduced continuation of the slow reaction in the previous gut section. Back reactions, due to instability of ligand-Cu complex and subsequent re-adsorption to sediment, might occur in any gut section; thus the cumulative $\mathrm{Cu}$ solubilization profile shown is not necessarily the same as the expected profile of $\mathrm{Cu}$ concentration. Gut absorption and secretion of dissolved $\mathrm{Cu}$ would also affect the increasing trend of $\mathrm{Cu}$ accumulation towards the posterior of the gut, but the lack of absorption and efflux data does not allow quantitative estimates. Nevertheless, this analysis indicates that the midgut of A. marina would face a dramatic increase in $\mathrm{Cu}$ exposure relative to the foregut. In contrast, lower AA concentrations in the gut fluid of $P$. californicus would remobilize only a fraction of available $\mathrm{Cu}$ in foregut and midgut, with no significant slow reactions (Figs. $1 \mathrm{~b} \& 5 \mathrm{~b}$ ).

Extremely low activity of free metal ions in gut fluid (Chen \& Mayer 1998a, b) suggests that metal-ligand complexes, in addition to ionic forms, are the available species for metal absorption in guts. Absorption of metal-ligand complexes may follow that of smaller organic molecules (i.e. AA) via either passive diffusion or carrier-mediated pathways (Self et al. 1995). The association of significant fractions of metals in low molecular weight fractions ( $<3 \mathrm{kDa}$; Chen 1997, Chen \& Mayer 1998b) provides such a possibility. Furthermore, $\mathrm{Cu}$ concentrations along the guts apparently paralleled those of AA found among various species of deposit and suspension feeders in their natural habitats (Table 1), corroborating this hypothesis. The formation of neutral metal-ligand complexes during in vitro digestion, in addition to the build-up of high metal concentrations at the mid-hindgut, may facilitate absorption of metals via passive diffusion (Andersen \& Nielsen 1991, Phinney \& Bruland 1994). Carriermediated pathways, designed specifically for the AA ligands, may be hindered by conformational changes of organic ligands during the formation of metal complexes and by potential interference of metal with the proteinaceous carrier systems.

Sedimentary metals remobilized during deposit feeding may be toxic to the digestive systems, as well as to other organismal functions (e.g. respiration, reproduction!. In a previous study, we observed that sufficient $\mathrm{Cu}$ from contaminated sediments could inhibit digestive proteases of Arenicola marina (Chen \&
Mayer 1998a). This threshold AA:Cu ratio was found to be about 300 during in vitro digestion, which sets up the basis for a toxicological parameter for $\mathrm{Cu}$-contaminated sediments. This toxicological ratio is also applicable to deposit-feeding holothuroids (Chen \& Mayer unpubl. data). Using this ratio, the threshold bioavailable $\mathrm{Cu}$ concentrations encountered in this study can be calculated as 4020,160 , and $210 \mu \mathrm{M} \mathrm{g}^{-1}$ sediment for gut fluid of $A$. marina, Parastichopus californicus and Cucumaria frondosa, respectively, given their respective AA concentrations (Fig. 3). Therefore, in A. marina experiments, it took about $140 \mathrm{~min}$ to reach the threshold $\mathrm{Cu}$ concentration in the $\mathrm{BH}$ sediment (Fig. 1a), which is longer than the GRT of this species (McLeod 1994), while $\mathrm{Cu}$ concentrations in sediments PH1 and PH2 did not reach the threshold over the entire $4 \mathrm{~h}$ incubation (Fig. 1j). This analysis suggests that the release of sedimentary $\mathrm{Cu}$ would not inhibit proteases of $A$. marina in vivo, because the sediments would spend only a fraction of the GRT in the midgut section (Fig. 5a). In contrast, the remobilized $\mathrm{Cu}$ concentrations in the 2 holothuroid species would reach inhibition threshold levels within minutes of incubation (Fig. $1 \mathrm{~b}-\mathrm{c}, \mathrm{k}-\mathrm{l}$ ), suggesting their greater susceptibility to $\mathrm{Cu}$-contaminated sediments. These calculations indicate that given the same type of $\mathrm{Cu}$ contaminated sediments, animals with poor ability to dissolve $\mathrm{Cu}$ (due to lower gut ligand concentrations) are the most susceptible to toxification of digestive proteases within the gut. This counterintuitive result derives from the fact that $\mathrm{Cu}$ solubilization at lower gut AA to sedimentary $\mathrm{Cu}$ ratios is dominated by the fast reaction, and the toxification effects can set in within a short period of time $(\leq 2 \mathrm{~min})$.

Assuming that pelletized sediments move through the gut at a constant volumetric rate (continuous feeding and plug-flow; Penry \& Jumars 1990), time to travel through a gut section should be proportional to its length, which means that only a fraction of GRT is used for digestion and dissolution (Fig. 5). This digestive constraint, in addition to the effects of gut ligand concentrations on kinetics (Fig. 1), has important implications for better understanding sedimentary metal bioavailabilities via in vitro digestion experiments. First, incubation time during an in vitro digestion should be adjusted according to the GRT and gut morphology of the species concerned. In addition, the variation in chemical composition of digestive fluids among gut sections (Mayer et al. 1997) should be taken into consideration in order to measure metal exposure within each gut section. Based on the metal exposure data in each gut section, the cumulative metal exposure during 1 digestive pass of deposit feeding can be calculated by integrating the metal concentration expressed as Eq. (1) over the fraction of 
GRT in each gut section. Finally, the removal term for the dissolved metals, including re-adsorption onto sediment and gut absorption, should also be studied in order to bridge sedimentary metal dissolution with bioaccumulation.

\section{Implications for biogeochemical cycling of metals}

Several lines of evidence presented in this and earlier studies strongly suggest that digestive solubilization or remobilization of sedimentary metals occurs under field conditions. A striking positive relationship between in vivo metal and AA concentrations was also revealed among digestive fluid of 8 species of invertebrates (Chen 1997), and along gut sections (Table 1; Chen 1997), suggesting a close link between digestive activity and metal solubilization. The results indicate that digestively enhanced solubilization occurs much faster than previously recognized, sedimentary diagenetic processes (Aller 1978). Much higher concentrations of metals ( $>1$ to 2 orders of magnitude) were released by digestive fluid, relative to seawater controls, in the time frame of hundreds of minutes (Mayer et al. 1996; Fig. 1), in comparison to a much smaller release within tens of days in microbially mediated diagenesis (Gerringa 1990, 1991, Paulson et al. 1991). Bioturbation by benthic organisms, including feeding and burrowing, can alleviate somewhat the diffusional limitation, but early studies mainly focused on the effects of physical mixing (Bosworth \& Thibodeaux 1990) and downward circulation of oxygenated water through extended burrow systems (Aller 1978). For example, a modeling study (Thomann et al. 1993) suggested that physical mixing alone can stimulate the rates of early diagenesis and the efflux of sedimentary metals by an order of magnitude. Our results (Mayer et al. 1996) thus indicate that this magnitude of enhancement by bioturbation in Thomann et al. (1993) is probably a substantial underestimate because it did not include digestion. Incorporation of digestion effects into a bioturbation model (e.g. Thomann et al. 1993) requires accurate estimation of sedimeni reworking rates by various species of deposit feeders, but such data are available for only a few systems (Cadée 1976).

The biogeochemical cycle of metals could be altered should the dissolved sedimentary metals be excreted by the organisms. Complexation with dissolved organic ligands will greatly increase the solubility of many transition metals, result in longer residence times of these metals in the water column, and thus greater mobility in the environment (Donat \& Bruland 1995). Re-adsorption of metal-ligand complexes during digestion may change sedimentary metal speciation. converting inorganic to organic solid phases.

\section{Conclusions}

The time-resolved in vitro digestion experiments in this study show that bioavailability of sedimentary metals during deposit feeding is not a single-value parameter. Rather, it varies as a function of dissolved gut amino acids (AA), gut retention time, sedimentary metal loading and species of organisms, and hence is a product of sediment-organism interactions. The complex nature of bioavailability is created by the spectrum of sedimentary metals with varying lability interacting with a spectrum of metal-binding sites in gut fluid. In general, higher lability of sedimentary metals occurs when organisms with high AA concentrations feed on high metal-loaded sediments. As a result of these interactions, the solubilization of sedimentary metals during in vitro digestion were biphasic, with an initial rapid step (F-transfer) followed by a slower reaction (S-transfer). Variations in the ratio of gut ligand to sedimentary metal concentrations appear to influence the relative importance of $F$-and $\mathrm{S}$-transfers in certain sediment-organism combinations, with an increasing ligand to metal ratio enhancing the importance of S-transfer. Because inhibition of digestive protease by solubilized sedimentary $\mathrm{Cu}$ occurs at gut $\mathrm{AA}: \mathrm{Cu}$ ratios $\leq 300$ (Chen \& Mayer 1998a), toxification of digestive enzymes is predicted to occur more readily in species with lower gut AA concentrations. Multiple extraction experiments revealed that metal bioavailability to a single organism may differ substantially from that to a community of organisms.

Acknowledgements. We thank Peter Jumars for many helpful comments on the manuscript, Samuel Luoma for in-depth. discussions and Linda Schick, Fred Short and Liko Self for assistance in lab and field. The research was supported by the Office of Naval Research. Contribution No. 324 from the Darling Marine Center.

\section{LITERATURE CITED}

Aller RC (1978) Experimental studies of changes produced by deposit feeders on pore water, sediment and overlying water chemistry. Am J Sci 278:1185-1234

Andersen O, Nielsen JB (1991) Effects of DDC and related compounds on cadmium toxicokinetics. In: Merian E, Haerdi W (eds) Metal compounds in environment and life 4: interrelation between chemistry and biology. Science and Technology Letters and Science Reviews Inc, Chicago, p 251-259

Ashmead HD (1991) Comparative intestinal absorption and subsequent metabolism of metal amino acid chelates and inorganic metal salts. In: Subramanian KS, Iyengar GV, Okamoto K (eds) Biological trace element research: multidisciplinary perspectives. American Chemical Society, Washington, DC, p 306-319

Baffi F, Ianni MC, Ravera M, Magi E (1994) Study of the influ- 
ence of free dissolved amino acids on copper (II) adsorption/remobilization from inorganic fractions of marine sediments using a reversed-phase liquid chromatographic procedure. Anal Chim Acta 294:127-134

Bosworth WS, Thibodeaux LJ (1990) Bioturbation: a facilitator of contaminant transport in bed sediment. Environ Prog 9:211-217

Cadée GC (1976) Sediment reworking by Arenicola marina on tidal flats in the Dutch Wadden sea. Neth J Sea Res 10: $440-460$

Calmano W, Ahlf W, Forstner U (1988) Study of metal sorption/desorption processes on competing sediment components with a multichamber device. Environ Geol Water Sci 11:77-84

Cammen LM (1980) Ingestion rate: an empirical model for aquatic deposit feeders and detritivores. Oecologia 44 $303-310$

Chen $Z$ (1997) Bioavailability of heavy metals in sediments $\mathrm{PhD}$ dissertation, University of Maine, Walpole

Chen Z, Mayer LM (1998a) Digestive proteases of the lugworm (Arenicola marina) inhibited by $\mathrm{Cu}$ from contaminated sediments. Environ Toxicol Chem 17:433-438

Chen Z, Mayer LM (1998b) Mechanisms of Cu solubilization during deposit feeding. Environ Sci Technol 32:770-775

Diallo MS, Abriola LM, Weber WJ Jr (1994) Solubilization of nonaqueous phase liquid hydrocarbons in micellar solutions of dodecyl alcohol ethoxylates. Environ Sci Technol 28:1829-1837

Donat JR, Bruland KW (1995) Trace elements in the oceans In: Salbu B, Steinnes E (eds) Trace elements in natural waters. CRC Press, Boca Raton, FL, p 247-281

Elliott HA, Huang CP (1979) The effect of complex formation on the adsorption characteristics of heavy metals. Environ Int 2:145-155

Elliott HA, Huang CP (1980) Adsorption of some Cu(II)-amino acid complexes at the solid-solution interface. Effect of ligand and surface hydrophobicity. Environ Sci Technol $14: 87-93$

Elliott HA, Huang CP (1981) Adsorption characteristics of some $\mathrm{Cu}(\mathrm{II})$ complexes on aluminosilicates. Water Res 15 : $849-855$

Fisher NS, Teyssie J, Fowler SW, Wang W (1996) Accumulation and retention of metals in mussels from food and water: a comparison under field and laboratory conditions. Environ Sci Technol 30:3232-3242

Gagnon C, Fisher NS (1997) The bioavailability of sedimentbound $\mathrm{Cd}, \mathrm{Co}$, and $\mathrm{Ag}$ to the mussel Mytilus edulis. Can J Fish Aquat Sci 54:147-156

Gerringa LJA (1990) Aerobic degradation of organic matter and the mobility of $\mathrm{Cu}, \mathrm{Cd}, \mathrm{Ni}, \mathrm{Pb}, \mathrm{Zn}, \mathrm{Fe}$ and $\mathrm{Mn}$ in marine sediment slurries. Mar Chem 29:355-374

Gerringa LJA (1991) Mobility of $\mathrm{Cu}, \mathrm{Cd}, \mathrm{Ni}, \mathrm{Pb}, \mathrm{Zn}, \mathrm{Fe}$, and $\mathrm{Mn}$ in marine sediment slurries under anaerobic conditions and at $20 \%$ air saturation. Neth J Sea Res 27: $145-156$

Harvey RW, Luoma SN (1985a) Separation of solute and particulate vectors of heavy metal uptake in controlled suspension-feeding experiments with Macoma balthica. Hydrobiologia 121:97-102

Harvey RW, Luoma SN (1985b) Effect of adherent bacteria and bacterial extracellular polymers upon assimilation by Macoma balthica of sediment-bound $\mathrm{Cd}, \mathrm{Zn}$, and Ag. Mar

Editorial responsibility: Otto Kinne (Editor), Oldendorf/Luhe, Germany
Ecol Prog Ser 22:281-289

Jordan AJ (1972) On the ecology and behavior of Cucumaria frondosa (Echinodermata: Holothuriodea) at Lamoine Beach, Maine. MS thesis, University of Maine, Walpole

Kaganovskaya EA (1983) The electron microscope study of the stomach epithelium of the polychaete Arenicola marina. Tsitologiya Leningr 21:650-656

Luoma SN, Jenne EA (1977) The availability of sedimentbound cobalt, silver, and zinc to a deposit-feeding clam. In: Wildung RE, Drucker $\mathrm{H}$ (eds) Biological implications of metals in the environment. NTIS FONF-750929, Springfield, VA, p 213-230

Mayer LM, Chen Z, Findlay RH, Fang J, Sampson S, Self RFL, Jumars PA, Quétel C, Donard OFX (1996) Bioavailability of sedimentary contaminants subject to deposit-feeder digestion. Environ Sci Technol 30:2641-2645

Mayer LM, Schick LL, Self RFL, Jumars PA, Findlay RH, Chen Z. Sampson S (1997) Digestive environments of benthic macroinvertebrate guts: enzymes, surfactants and dissolved organic matter. J Mar Res 55:785-812

McLeod IJ (1994) Extraction of sediment-bound lead using marine deposit-feeder gut fluids, with a discussion of the gut histologies and feeding and defecation behaviors of Amphitrite spp. and Arenicola marina (Polychaeta). MS thesis, University of Maine, Walpole

Paulson AJ, Curl HC, Cokelet ED (1991) Remobilization of $\mathrm{Cu}$ from marine particulate organic matter and from sewage. Mar Chem 33:41-60

Pecon J, Powell EN (1981) Effect of the amino acid histidine on the uptake of cadmium from the digestive system of the blue crab, Callinectes sapidus. Bull Environ Contam Toxicol 27:34-41

Penry DL (1989) Tests of kinematic models for depositfeeders' guts: patterns of sediment processing by Parastichopus californicus (Stimpson) (Holothuoidea) and Amphicteis scaphobranchiata Moore (Polychaeta). J Exp Mar Biol Ecol 128:127-146

Penry DL, Jumars PA (1990) Gut architecture, digestive constraints and feeding ecology of deposit-feeding and carnivorous polychaetes. Oecologia 82:1-11

Phinney JT, Bruland KW (1994) Uptake of lipophilic organic $\mathrm{Cu}, \mathrm{Cd}$ and $\mathrm{Pb}$ complexes in the coastal diatom Thalassiosira weissflogii. Environ Sci Technol 28:1781-1790

Self RFL, Jumars PA, Mayer LM (1995) In vitro amino acid and glucose uptake rates across the gut wall of a surface deposit feeder. J Exp Mar Biol Ecol 192:289-318

Taghon GL, Greene RR (1990) Effects of sediment-protein concentration on feeding and growth rates of Abarenicola pacifica Healy et Wells (Polychaeta: Arenicolidae). J Exp Mar Biol Ecol 136:197-216

Taghon GL, Jumars PA (1984) Variable ingestion rate and its role in optimal foraging behavior of marine deposit feeders. Ecology 65:549-558

Thomann RV, Merklin W, Wright B (1993) Modeling cadmium fate at superfund site: impact of bioturbation. J Environ Eng-ASCE 119:424-442

Thomann RV, Mahony JD, Mueller R (1995) Steady-state model of biota sediment accumulation factor for metals in two marine bivalves. Environ Toxicol Chem 14:1989-1998

Wang W, Fisher NS, Luoma SN (1996) Kinetic determinations of trace element bioaccumulation in the mussel Mytilus edulis. Mar Ecol Prog Ser 140:91-113

Submitted: January 27, 1998; Accepted: September 9, 1998 Proofs received from author(s): December 28, 1998 